\title{
Ultrafast Charge Carrier Dynamics in Extremely Thin Absorber (ETA) Solar Cells Consisting of CdSe-Coated ZnO Nanowires
}

Michael E. Edley, Siming Li, Glenn W. Guglietta, Hasti Majidi, and Jason B. Baxter*

Department of Chemical and Biological Engineering, Drexel University, Philadelphia, PA, 19104, USA

*Corresponding author. E-mail: jbaxter@drexel.edu. Ph: 215-895-2240, Fax: 215-895-5837

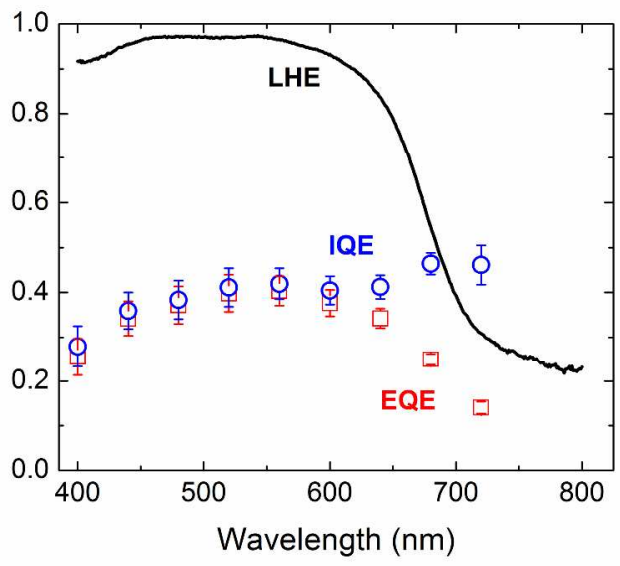

Figure S1. Light harvesting efficiency (LHE), internal quantum efficiency (IQE), and external quantum efficiency (EQE) of ETA solar cell. Samples consisted of $30 \mathrm{~nm}$ of CdSe on a $5 \mathrm{~nm}$ CdS interlayer on $\mathrm{ZnO}$ nanowires that were $50 \mathrm{~nm}$ in diameter and $1000 \mathrm{~nm}$ long. Reproduced from our Reference S1. 


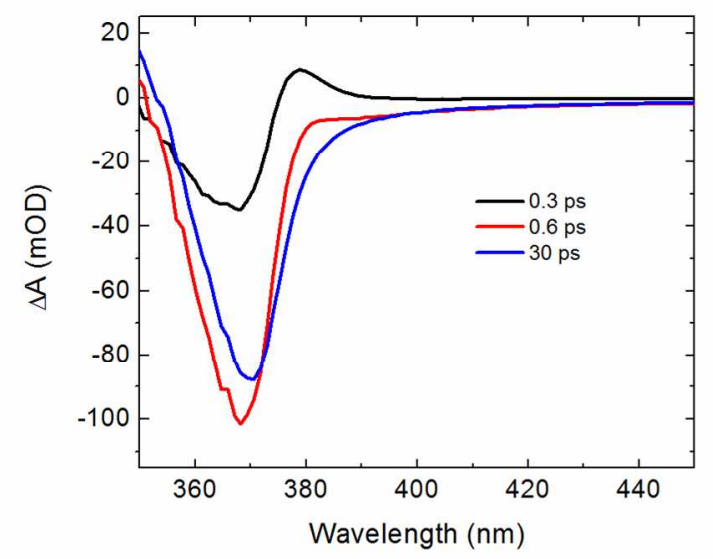

Figure S2. TA spectra of bare $\mathrm{ZnO}$ nanowires at various time delays from 0.03 to $30 \mathrm{ps}$. Samples consist of $\mathrm{ZnO}$ nanowires that were $50 \mathrm{~nm}$ in diameter and $500 \mathrm{~nm}$ long. Samples were pumped at $325 \mathrm{~nm}$ with pulse energy of $400 \mu \mathrm{J} \mathrm{cm}^{-2}$.
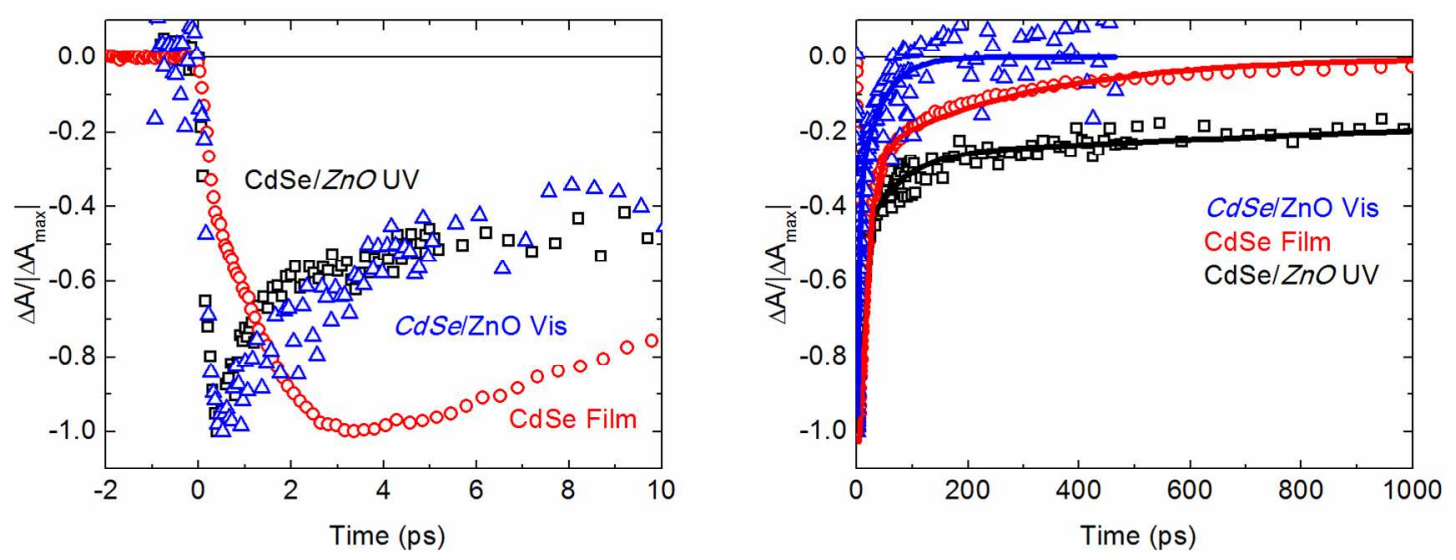

Figure S3. (a) Short time and (b) long time dynamics of the CdSe-coated ZnO nanowires, without CdS, in Figure $4 \mathrm{~b}$ probed at the $\mathrm{CdSe}$ band edge (blue) and at the $\mathrm{ZnO}$ band edge (black). Samples were pumped at $450 \mathrm{~nm}$ with pulse energy of $710 \mu \mathrm{J} \mathrm{cm}^{-2}$. The dynamics of a planar $150 \mathrm{~nm}$ CdSe film pumped with a pulse energy of $570 \mu \mathrm{J} \mathrm{cm}^{-2}$ and probed at the CdSe band edge are shown in red.

\section{References}

S1. H. Majidi, M.E. Edley, L. Spangler and J.B. Baxter, "Tailoring Absorber Thickness and the AbsorberScaffold Interface in CdSe-Coated ZnO Nanowire Extremely Thin Absorber Solar Cells," Electrochim. Acta, 145, 291 (2014). 